\title{
What evidence exists for changes in the occurrence, frequency or severity of human health impacts resulting from exposure to alien invasive species in Europe? A systematic map protocol
}

\author{
Helen R Bayliss', Stefan Schindler ${ }^{2,3 *}$, Franz Ess| ${ }^{2,3}$, Wolfgang Rabitsch ${ }^{2}$ and Andrew S Pullin ${ }^{1}$
}

\begin{abstract}
Background: Invasive alien species are of global concern due to their impacts on biodiversity, related ecosystem services and on economy. A number of invasive alien species are also responsible for human health impacts, either as carriers (vectors) of pathogens, as causal agents of toxic or allergic reactions (e.g. to pollen or insect stings) or injuries. However, there has been relatively little attention given to these human health effects in invasion ecology literature, with no attempts to systematically identify and quantify evidence of impacts. It is likely that further invasive alien species will benefit from global change as some invasive traits provide high plasticity and therefore support adaptation capacities to cope with changing conditions. Thus, global change may lead to new public health concerns as invasive alien species expand their range or enter new areas, or may alter the severity of health impacts by changing the physiology or quantity of potential allergens or irritants produced. This mapping review aims at identifying any evidence for changes in the occurrence, frequency or severity of human health impacts resulting from exposure to invasive alien species in Europe over the last 25 years.

Methods/Design: A systematic search of both ecological and medical literature will be used to identify potentially relevant studies using three a priori inclusion criteria, i.e. (i) affected human population in Europe, (ii) exposure to alien species, (iii) change in health impact. Studies will be assessed against inclusion criteria at title, abstract and full text to determine relevance to the mapping review. Studies deemed relevant will be coded using predetermined categories relating to the review inclusion criteria and study design, and recorded in a searchable database. Depending on the information available, studies may also be geo-referenced to create a geographic map of the evidence. Descriptive statistics will be used to explore key trends in the evidence base. The searchable database of studies and their main characteristics will be made available with the final report. It is intended that this systematic map will be useful in informing decision making related to the future human health impacts of invasive alien species in Europe.
\end{abstract}

Keywords: Allergens, Biological invasions, Bites or stings, Dermatitis, Disease, Public health

\footnotetext{
* Correspondence: stefan.schindler@umweltbundesamt.at

${ }^{2}$ Department of Biodiversity and Nature Conservation, Environment Agency

Austria, Spittelauer Lände 5, 1090 Vienna, Austria

${ }^{3}$ University of Vienna, Division of Conservation Biology, Vegetation and

Landscape Ecology, Rennweg 14, 1030 Vienna, Austria

Full list of author information is available at the end of the article
} 


\section{Background}

Invasive species have been associated with a range of health impacts, including injuries (such as bites, stings, scratches, rashes), transmission of diseases and parasites to humans as a vector or a reservoir, bioaccumulation of noxious substances, or through reactions to secondary plant compounds, toxins or allergen substances such as pollen [1,2]. Within Europe, over 170 species of mammals, birds and reptiles with accompanying parasites of human concern have established [1,3]. Several invasive plant species are also associated with health impacts. Some species, such as Ambrosia artemisiifolia, produce pollen that can trigger an allergic reaction with hay fever-like symptoms [4-7], while the sap of giant hogweed Heracleum mantegazzianum leads to severe dermal blistering and sensitivity to sunlight [8]. Invasive insect species may also pose a risk to human health: the Asian Tiger mosquito Aedes albopictus and several other Aedes spp. are effective vectors of human diseases such as Dengue Feaver and Chikungunya [9]; the Asian hornet Vespa velutina has been accidentally introduced to France from China and is responsible for painful stings [10]; while some caterpillars, for example of the oak processionary moth Thaumetopoea processionea which has recently been introduced to the UK, produce irritating hairs that cause skin and respiratory complaints [11]. Despite this, there have been no attempts to systematically identify or quantify the extent of invasive species impacts on human health. Previous reviews suggest that research on this topic is biased towards a few species [12], hindering a balanced understanding of the scale, patterns and trends of these impacts [Schindler S, Staska B,
Adam M, Rabitsch W, Essl F: Alien species and public health impacts in Europe: a synthesis, submitted]. Without this knowledge, it will be difficult to prepare appropriate and timely public health responses to emerging threats in the face of climate change.

Globalisation affects invasive species through a range of mechanisms. Increasing transport infrastructures and the opening of new routes may lead to the spread of alien species and their diseases $[13,14]$. Climatic changes may affect transport and introduction mechanisms, facilitating the establishment of new invasive alien species and altering the distribution and impacts of already present species and their responses to management [15]. Invasive alien species are likely to benefit from climate change as some invasive traits provide high plasticity and therefore support adaptation capacities to cope with changing conditions [15-17]. Global change may lead to new public health concerns as invasive alien species expand their range or enter new areas, or may alter the severity of health impacts by changing the physiology or quantity of potential allergens or irritants produced (Figure 1). An understanding of these potential changes is crucial for informing effective future public health policies. This systematic map will form part of a wider project that synthesises evidence on emerging threats to human health from alien species in Europe under climate change and derives recommendations for environmental and medical mitigation.

\section{Objective of the review}

The aim of this review is to use recognised systematic mapping methods (e.g. Collaboration for Environmental

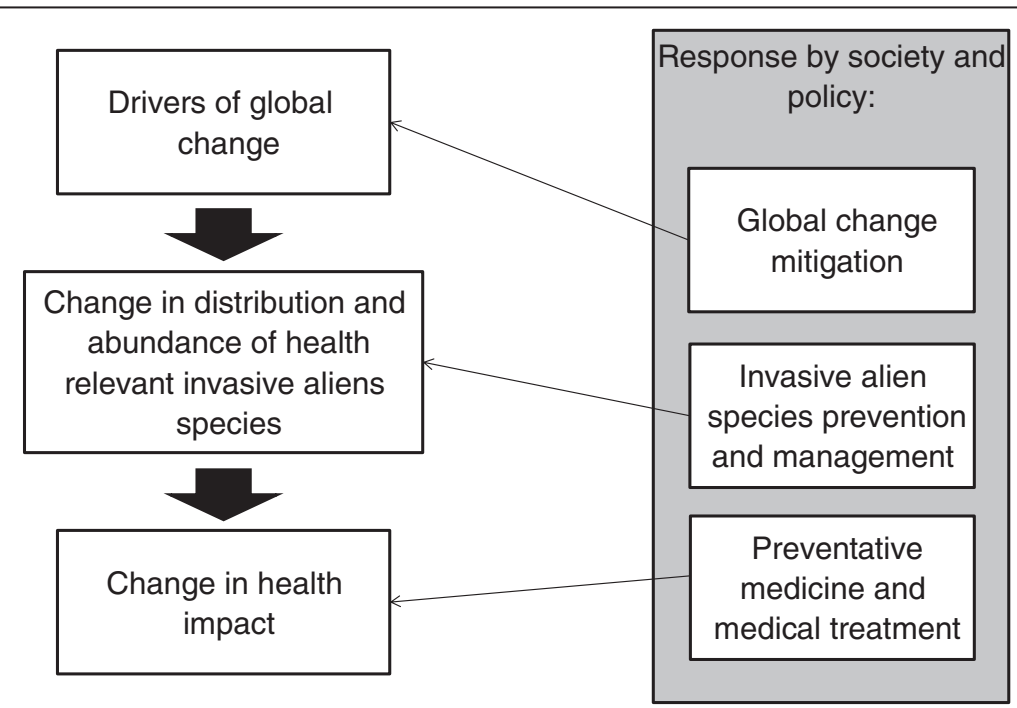

Figure 1 Drivers of global change cause changes in the distribution and abundance of health- relevant invasive alien species. These changes subsequently lead to a change in human health impact, the topic of this synthesis. Responses by society and policy aiming at the mitigation of global change and the management of invasive alien species are currently increasing, but still not implemented in sufficient amount to halt global change and invasions of alien species [25]. Thus, medical treatment of invasive alien species' health impacts is often required. 
Evidence, [18]) to identify the current state and distribution of evidence of changing human health impacts from invasive alien species in Europe over the last 25 years. The evidence base identified by the systematic mapping process will be explored to find data-rich areas suitable for subsequent focused systematic reviews and to identify key knowledge gaps.

Primary question: What evidence exists for changes in the occurrence, severity or frequency of human health impacts resulting from exposure to invasive alien species in Europe?

The question consists of the following components:

Population: Any human population in Europe Exposure: Alien species present in Europe that cause human health impacts since 1990

Comparator: No contact or less frequent or severe contact

Outcome: Change in the occurrence, frequency or severity of health impacts in human populations

\section{Methods}

\section{Search strategy}

The aim of the search is to undertake a comprehensive and unbiased survey of the available literature relating to the systematic map question published since 1990. Terms relating to both the exposure (invasive species) and the outcome (health impacts) will be combined and searched in a range of databases and other sources to maximise the relevant results returned. All searches, sources, dates and the number of hits retrieved will be recorded for inclusion in the final systematic map report appendices and the results of searches exported into reference management software to facilitate review management wherever possible.

\section{Search terms}

All database searches will be conducted in the English language. Potentially retrieved non-English language articles will be recorded in an appendix, and may be included in the final systematic map if resources allow. Searches will be conducted using generic exposure and outcome keywords that have been refined through scoping (Additional file 1) and Latin species names (Additional file 2). Species names have been compiled from existing studies ([1,12], Schindler S, Staska B, Adam M, Rabitsch W, Essl F: Alien species and public health impacts in Europe: a synthesis, submitted) and from records in the IUCN SSC Invasive Species Specialist Group Global Invasive Species Database (www.issg.org/database/welcome) that report human health impacts and presence of species in Europe (even if the health impacts are not reported from within Europe). Search terms relating to the population, and specifically to the location of Europe, will not be used but applied as a filter to studies retrieved by the searches. Search strings will be adapted for each particular database to enable an efficient search, for instance we will remove generic health terms (e.g. health, "human health") for searches conducted in medical databases. Generic exposure search terms and Latin species names will be searched in combination with the general outcome search terms identified below:

\section{Exposure search terms:}

- ("invasive species" OR alien OR "non-native" OR exotic OR "introduced species" OR "non-indigenous" OR weed)

\section{Outcome search terms:}

- (allerg* OR hay-fever OR asthma OR dermatitis OR bite OR biting OR sting*OR toxic* OR poison" OR venom* OR irrita*) AND health

- (disease OR outbreak OR epidemic OR parasit* OR vector OR host OR reservoir) AND ("human health" OR "public health")

\section{Databases}

The following scientific and medical databases will be searched using the terms above to identify studies relevant to the question, using limits to refine results to studies published during or after 1990:

- Web of Science

- MEDLINE

- CINAHL

- CAB Direct including CAB Abstracts and Global Health

- EMBASE

- SCOPUS

- TOXNET including DART (Developmental \& Reproductive Toxicology)

- Armed Forces Pest Management Board Literature Retrieval System

\section{Search engines}

The general key words identified above will be entered into the advanced search function of Google Scholar (scholar.google.com) and the first 100 hits exported for assessment against the inclusion criteria. This will provide a further comprehensiveness check to test if any sections of the literature are missed by the main search.

\section{Specialist sources}

Relevant species will be searched for in the following specialist sources to identify references to human health impacts: 
- Global Invasive Species Database (GISD): www.issg. org/database/welcome

- European Alien Species Information Network (EASIN): http://easin.jrc.ec.europa.eu/

- Delivering Alien Invasive Species Inventories for Europe (DAISIE): www.europe-aliens.org

- CABI Invasive Species Compendium: http://www.cabi.org/isc

- European Network on Invasive Alien Species (NOBANIS): http://www.nobanis.org

- GB Non-native Species (GB NNSS) Species Information Portal: http://www.nonnativespecies. org/factsheet/index.cfm

- The Mediterranean Science Commission (CIESM): http://www.ciesm.org/online/atlas/index.htm

The following health sources will also be searched to identify relevant records:

- European Centre for Disease Prevention and Control: http://www.ecdc.europa.eu/en/Pages/ home.aspx

- Robert Koch Institute: http://www.rki.de/EN/ Home/homepage_node.html

- TropNet Surveillance News and Events: tropnet.net

All issues of the following journals will also be searched online for relevant articles as there are currently not indexed in the databases:

- NeoBiota: http://www.pensoft.net/journals/neobiota/

- Management of Biological Invasions: http://www. reabic.net/journals/mbi/

- BioInvasion Records: http://www.reabic.net/ journals/bir/

Early view articles and the three most recent issues of the following journals will also be searched online for relevant articles:

- Biological Invasions: http://www.springer.com/ life+sciences/ecology/journal/10530

- Aquatic Invasions: http://www.aquaticinvasions.net/

\section{Supplementary searches}

The reference lists of retrieved review articles will be checked to ensure that any relevant articles are captured and included into the search record.

\section{Search comprehensiveness assessment}

The comprehensiveness of the searches was tested by running Web of Science searches with the search terms identified during scoping and then checking the results for six 'control' papers $[1,7,9,12,19,20]$ to ensure that all were being detected by the search terms proposed. All six papers were detected by the proposed searches. The control papers were selected as they contained a combination of review articles and primary studies and covered a range of different key words:

\section{Study inclusion criteria}

All studies retrieved by the searches will be assessed at title, abstract and full text (as appropriate) against the following study inclusion criteria to ensure that only relevant articles are admitted to the systematic map. A, subset of 100 studies or $10 \%$ of the total results retrieved by the searches (whichever is highest) will be checked against the inclusion criteria at title and abstract by two independent reviewers and a kappa test used to determine agreement, with 0.6 or above indicating substantial agreement. Any disagreements will be discussed and any definitions that require clarifying will be adjusted accordingly. Studies will be included in the systematic map database if they meet the following inclusion criteria:

Population: Any human population in Europe (as defined politically but excluding overseas territories).

Exposure: Species alien to Europe or being native in parts of Europe but alien to others that cause negative impacts on human health. Here we define alien species as species transported by direct or indirect human agency beyond the biogeographic limits of their past or present geographic ranges into areas in which they do not naturally occur [21,22]. For the purposes of this map, we are including alien vector species (e.g. mosquitos, ticks, sandflies), which may carry and transmit infectious pathogens to humans, and alien reservoir species (e.g. mammals, birds and reptiles), which are intermediate or long-term hosts of pathogens of infectious diseases (categories 1b, 2a, 2b and 2c under the framework identified by [12]), but we exclude pathogens, domestic animals that serve as vectors or reservoirs, and European species that do not fall under the definition of alien species above.

Comparator: No contact or less frequent or severe contact. Any time series or spatial comparison.

Outcome: Change in the occurrence, frequency or severity of health impacts in human populations in Europe since 1990.

Study design: All study designs will be included at this stage of the systematic map to be coded later on and presented in the results.

Studies excluded at full text will be listed in an appendix, together with reasons for exclusion.

\section{Study quality assessment}

Study quality will not be directly assessed as part of the systematic mapping process [18]. However, during data extraction, information relating to study type, study scale, and study design will be recorded and coded, giving an 
indication of the extent and robustness of evidence of individual included studies.

\section{Map coding}

All studies deemed relevant will be coded using a standard coding tool for inclusion into the systematic map database. Study coding using Google Forms as per Bottrill et al. [23] will be piloted, allowing automatic inclusion of entered data into a database. Studies will be coded for four types of information:

1. Bibliographic information
a. Publication type
b. Year

2. Information relating to the inclusion criteria

a. Population i: Human population affected

b. Population ii: Location of exposure

c. Population iii: Location of reported impact

d. Population iv: Activity of population at exposure

e. Exposure i: Taxonomic group of the invasive species

f. Exposure ii: Species name (binomial) of the invasive species

g. Exposure iii: Biome at location of exposure

h. Exposure iv: Habitat at location of exposure

i. Outcome i: Type of human health impact (disease or pathogen transmission/allergen or irritant)

j. Outcome ii: Specific condition (type of injury, allergy, dermatitis, disease)

k. Outcome iii: Change in human health impact (occurrence/frequency/severity)

3. Information relating to the study

a. Study type (e.g. patient case study, RCT)

b. Study design (sampling size, etc.)

c. Spatial scale of reported impact

d. Comparators

e. Timescale

f. Other factors affecting the outcome

4. Additional information relating to the species of concern
a. Geographic origin (native range)
b. Pathway of introduction (following the classification of Hulme et al. [24])

\section{Data synthesis and presentation}

Once relevant studies have been assessed and coded, the data will be included in a searchable database, and if possible, in a spatially-referenced map. This could be used by decision makers to identify species of concern in neighbouring countries, or to look at the evidence for impacts of specific species across Europe. Descriptive statistics relating to key trends in the final dataset will also be presented in the final systematic map report, including correlative analyses exploring relationships between the different question components.

\section{Additional files}

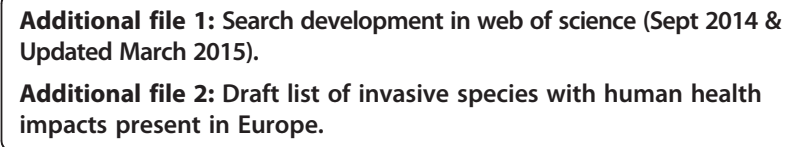

Additional file 2: Draft list of invasive species with human health

impacts present in Europe.

\section{Competing interests}

The authors declare that they have no competing interests.

\section{Authors' contributions}

$H B, A P$ and SS drafted the protocol with input from FE and WR. All authors read and approved the final manuscript.

\section{Acknowledgements}

We thank Hans-Peter Hutter, Peter Wallner and two anonymous referees for their very helpful suggestions.

\section{Sources of support}

This project is funded under the Austrian Climate and Energy Fund within the framework of the "ACRP" Program (Project Number KR13AC6K11141).

\section{Author details}

${ }^{1}$ Centre for Evidence-Based Conservation, School of the Environment, Natural Resources and Geography, Bangor University, Bangor LL57 2UW, UK.

${ }^{2}$ Department of Biodiversity and Nature Conservation, Environment Agency Austria, Spittelauer Lände 5, 1090 Vienna, Austria. ${ }^{3}$ University of Vienna, Division of Conservation Biology, Vegetation and Landscape Ecology, Rennweg 14, 1030 Vienna, Austria.

Received: 20 November 2014 Accepted: 26 March 2015

Published online: 12 April 2015

\section{References}

1. Hulme PE. Invasive species challenge the global response to emerging diseases. Trends Parasitol. 2014;30:267-70.

2. Roy H, Schonrogge $K$, Dean H, Peyton J, Branquart E, Vanderhoeven S, et al. Invasive alien species - framework for the identification of invasive alien species of EU concern, Report to the EU ENV.B.2/ETU/2013/0026. 2014.

3. DAISIE. Handbook of alien species in Europe. Dordrecht: Springer; 2009. ISBN 978-1-4020-8279-5.

4. Belmonte J, Vilà M. Atmospheric invasion of non-native pollen in the Mediterranean region. Am J Bot. 2004;91:1243-50.

5. Vilà M, Basnou C, Pyšek P, Josefsson M, Genovesi P, Gollasch S, et al. How well do we understand the impacts of alien species on ecosystem services? A pan-European, cross-taxa assessment. Front Ecol Environ. 2010;8:135-44.

6. Bullock J, Chapman D, Schaffer S, Roy D, Girardello M, Haynes T. Assessing and controlling the spread and the effects of common ragweed in Europe (ENV.B2/ETU/2010/0037), European Commission, Final Report. 2012.

7. Richter R, Berger UE, Dullinger S, Essl F, Leitner M, Smith M, et al. Spread of invasive ragweed: Climate change, management and how to reduce allergy costs. J Appl Ecol. 2013;50:1422-30.

8. Pyšek P, Cock MJW, Nentwig W, Ravn HP. Ecology and management of giant hogweed (Heracleum mantegazzianum). Wallingford (UK): CABl; 2007.

9. Medlock JM, Hansford KM, Schaffner F, Versteirt V, Hendrickx G, Zeller H, et al. A review of the invasive mosquitoes in Europe: Ecology, public health risks, and control options. Vec Borne Zoon Dis. 2012;12:435-47.

10. De Haro L, Labadie M, Chanseau P, Cabot C, Blanc-Brisset I, Penouil F, et al. Medical consequences of the Asian black hornet (Vespa velutina) invasion in Southwestern France. Toxicon. 2010;55:650-2.

11. Mindlin MJ, le Polain de Waroux O, Case S, Walsh B. The arrival of oak processionary moth, a novel cause of itchy dermatitis, in the UK: Experience, lessons and recommendations. Public Health. 2012;126:778-81.

12. Mazza G, Tricarico E, Genovesi P, Gherardi F. Biological invaders are threats to human health: an overview. Ethol Ecol Evol. 2014;26:112-29. 
13. Tatem AJ, Rogers DJ, Hay SI. Global transport networks and infectious disease spread. Adv Parasitol. 2006;62:293-343.

14. Essl F, Dullinger $S$, Rabitsch W, Hulme PE, Hülber $K$, Jarošík V, et al. Socioeconomic legacy yields an invasion debt. Proc Natl Acad Sci U S A. 2011;108(1):203-7.

15. Hellmann JJ, Byers JE, Bierwagen BG, Dukes JS. Five potential consequences of climate change for invasive species. Conserv Biol. 2008;22:534-43.

16. Dukes JS, Mooney HA. Does global change increase the success of biological invaders? Trends Ecol Evol. 1999;14:135-9.

17. Mooney HA, Hobbs RJ. Invasive species in a changing world. Washington: Island Press; 2000.

18. Collaboration for Environmental Evidence. Guidelines for Systematic Review and Evidence Synthesis in Environmental Management. Version 4.2. Environmental Evidence 2013, www.environmentalevidence.org/Documents/ Guidelines/Guidelines4.2.pdf

19. Öztürk B, Isinibilir M. An alien jellyfish Rhopilema nomadica and its impacts to the Eastern Mediterranean part of Turkey. J Black Sea/Medit Environ. 2010;16:149-56.

20. Bonizzoni M, Gasperi G, Chen X, James AA. The invasive mosquito species Aedes albopictus: current knowledge and future perspectives. Trends Parasitol. 2013;29:460-8.

21. Richardson DM, Pyšek P, Rejmánek M, Barbour MG, Panetta FD, West CJ. Naturalization and invasion of alien plants: concepts and definitions. Diversity Distrib. 2000;6:93-107.

22. Blackburn TM, Pyšek P, Bacher S, Carlton JT, Duncan RP, Jarošík V, et al. A proposed unified framework for biological invasions. Trends Ecol Evol. 2011;26:333-9

23. Bottrill M, Cheng S, Garside R, Wongbusarakum S, Roe D, Holland M, et al. What are the impacts of nature conservation interventions on human wellbeing: a systematic map protocol. Environ Evid. 2014;3:16.

24. Hulme PE, Bacher S, Kenis M, Klotz S, Kühn I, Minchin D, et al. Grasping at the routes of biological invasions: a framework for integrating pathways into policy. J Appl Ecol. 2008;45:403-14.

25. Tittensor DP, Walpole M, Hill SLL, Boyce DG, Britten GL, Burgess ND, et al. A mid -term analysis of progress towards international biodiversity targets. Science. 2014;346(6206):241-4.

\section{Submit your next manuscript to BioMed Central and take full advantage of:}

- Convenient online submission

- Thorough peer review

- No space constraints or color figure charges

- Immediate publication on acceptance

- Inclusion in PubMed, CAS, Scopus and Google Scholar

- Research which is freely available for redistribution 